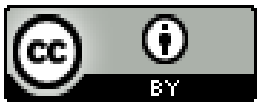

Esta obra está sob o direito de Licença Creative Commons Atribuição 4.0 Internacional.

\title{
SISTEMA DE INFORMAÇÃO GEOGRÁFICA APLICADA A SISTEMAS DE ABASTECIMENTO DE ÁGUAS: uma revisão sistemática integrativa
}

\author{
Adjair Altobelle Rufino Oliveira ${ }^{1}$ \\ Ana Benildes Campos Galindo ${ }^{2}$ \\ Eduardo Silva Laranjeira dos Santos ${ }^{3}$ \\ Sérgio Matheus Inácio Souza ${ }^{4}$ \\ Thainá Marques Gonçalves ${ }^{5}$ \\ Eduardo Cabral da Silva ${ }^{6}$
}

\section{RESUMO}

Os sistemas de abastecimento de águas são fundamentais para o desenvolvimento socioeconômico e, consequentemente, melhoria da qualidade de vida da população. $\mathrm{O}$ gerenciamento dos recursos hídricos e projetos sustentáveis e gerenciáveis são fundamentais para melhorar a otimização desses sistemas. Nesse sentido, surge o seguinte questionamento: quais as melhorias que o Sistema de Informação Geográfica pode trazer para os sistemas de abastecimento de águas? O presente trabalho busca, por meio de uma revisão sistemática integrativa, reunir trabalhos para verificar quais os impactos da utilização do SIG em sistemas de abastecimento de águas. As pesquisas foram realizadas nas bibliotecas do Periódicos CAPES e Scielo. Os resultados comprovam que com o auxílio das ferramentas de SIG, podem ser construídos indicadores para uma melhor avaliação do desempenho dos SAAs, com a finalidade avaliar o uso da ferramenta e sua organização quanto a espacialização de dados que facilitam a visualização dos problemas, auxiliando na tomada de decisão na concessionária de saneamento, além de ajudar a evitar e diminuir os eventuais gastos.

Palavras-chave: Abastecimento. Sustentabilidade. Gerenciamento. Avaliação de desempenho

\footnotetext{
1adjair1010@gmail.com

2ana.benildes@hotmail.com

${ }^{3}$ eduardosantos5421@gmail.com

${ }^{4}$ matheus_peu10hotmail.com

thainagmarques@hotmail.com

6eduardo.csilva@professores.unifavip.edu.br
} 


\section{INTRODUÇÃO}

O sistema de abastecimento de águas - SAA é um dos principiais serviços de utilidade pública e constitui um pilar do saneamento básico. Seu bom funcionamento tem grande importância para a melhoria da qualidade de vida da população, influenciando nos processos de desenvolvimento socioeconômicos, abrangendo assim, os setores de educação, turismo, produtividade e valorização imobiliária (INSTITUTO TRATA BRASIL, 2018).

A crescente demanda por água, principalmente das áreas urbanas, exige um melhor gerenciamento dos recursos hídricos pelas companhias, assim como, requer o desenvolvimento de projetos de SAA mais sustentáveis e gerenciáveis, com emprego de automatização e do Sistema de Informação Geográfica - SIG.

As ferramentas de análise e operação são de extrema eficiência para a manipulação do SIG, pois permite a compreensão de leitura, seja de grandes ou pequenas quantidade de dados que buscam fornecer resultados precisos na resolução dos conflitos e auxiliando na gestão integrada do sistema de abastecimento (SANTOS e PEREIRA, 2016).

Visando essa premissa, a utilização de ferramentas computacionais utilizados com modelos hidráulicos busca padronizar de forma geral os procedimentos e dar uma maior contribuição nos processos de operação, análise, planejamento com tomada de decisão no sistema de distribuição de água, dando uma solução mais viável para os complexos problemas de planejamento. (MUNDOGEO, 2018).

Atualmente pode se observar que muitas empresas de saneamento estão realizando pequenos experimentos com o geoprocessamento, antes de pensar na implantação definitiva dos SIG's, para ter informações praticas sobre essa nova tecnologia, analisando a viabilidade das funções de um SIG em um sistema de distribuição de água.

Diante do exposto, levanta-se a questão: quais as melhorias que o Sistema de Informação Geográfica pode trazer para o SAAs? Como hipótese, tem-se que diversos benefícios em termos de gestão de recursos hídricos serão alcançados, assim como, melhor gestão de operação dos SAAs.

O presente trabalho tem como objetivo avaliar os impactos da implantação do SIG nos SAAs por meio de uma revisão sistemática integrativa.

\section{MÉTODOLOGIA}

Para a revisão bibliográfica do presente trabalho foi adotada uma revisão sistemática integrativa que teve como base as buscas nas bibliotecas Periódico CAPES e Scielo, seguindo as etapas descritas no Quadro 1.

A partir da definição do tema, foi selecionada a pergunta norteadora, a escolha da estratégia de busca, os descritores e as bases de dados que apresentaram resultados mais expressivos. $\mathrm{Na}$ busca, foram utilizados os descritores SIG, abastecimento e saneamento conjugadas pelo operador booleano "And" para o levantamento das publicações. Posteriormente, foi definida a escolha dos critérios de inclusão e exclusão. Também foi analisada a identificação dos estudos pré-selecionados e selecionados através da leitura dos agentes indexadores das publicações de artigos publicados entre os anos de 2015 e 2021, como resumo, palavras-chave e título, bem como 
organização dos estudos pré-selecionados e identificação dos estudos selecionados.

Com a categorização dos estudos selecionados, foi feita uma elaboração e uso da matriz de síntese, além de análise das informações, formação de uma biblioteca individual e avaliação crítica dos estudos selecionados; para isso essa análise consistiu em fazer a interpretação e discussão dos resultados; apresentando para a revisão um formato de artigo, o qual contemple propostas para estudos futuros.

Sendo assim, os quadros apresentados neste artigo demostraram as etapas da revisão abrangente do sistema e os resultados obtidos diante da pesquisa. 


\section{QUADRO 1 \\ DETALHAMENTO DAS ETAPAS DA REVISÃO SISTEMÁTICA INTEGRATIVA.}

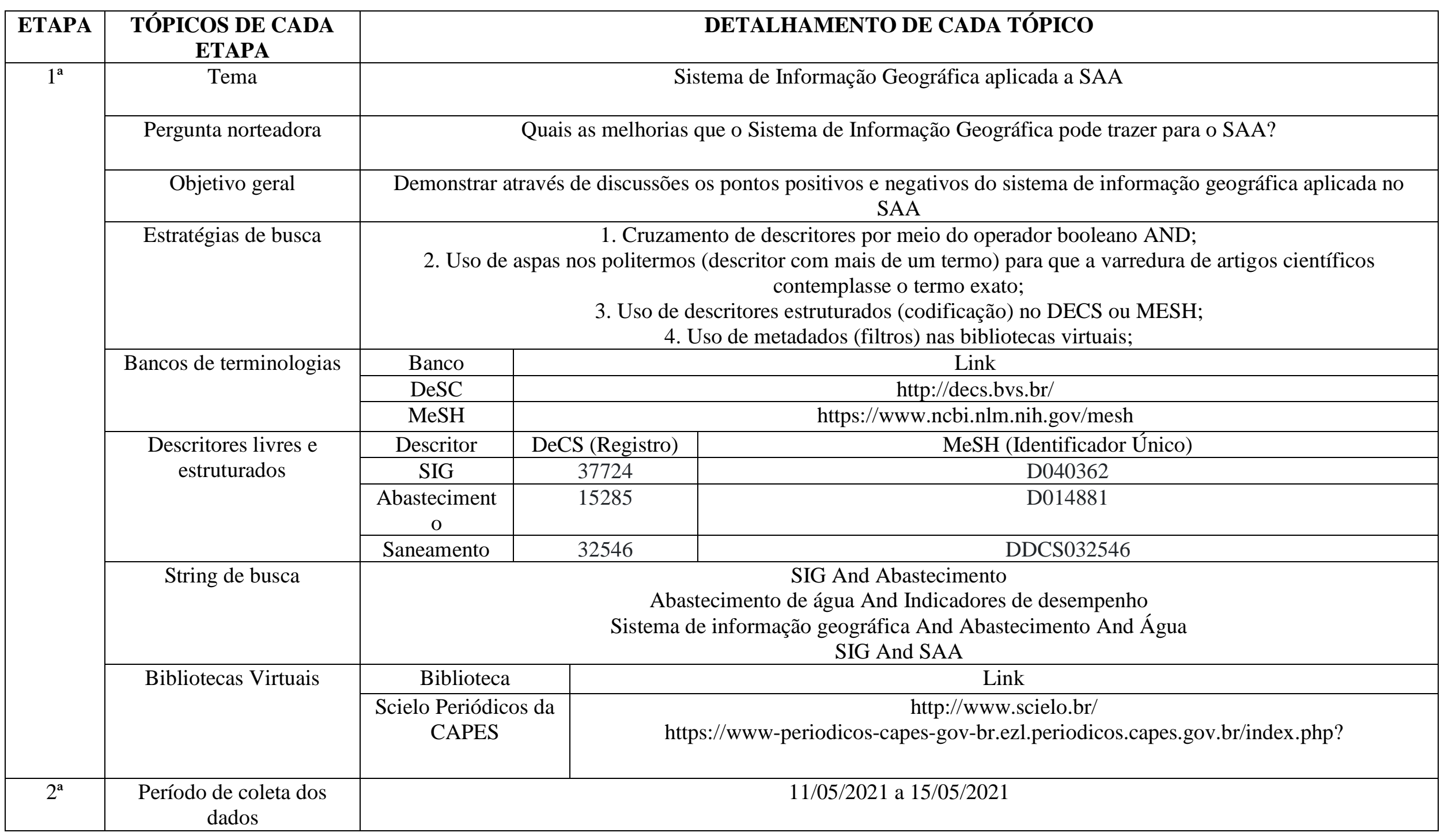




\begin{tabular}{|c|c|cc|}
\hline & Critérios de inclusão & 1. $\begin{array}{c}\text { Artigos (artigo científicos e free). } \\
\text { 2. Publicação (2015-2020). }\end{array}$ \\
\hline & Critérios de exclusão & 10 \\
\hline $3^{\mathrm{a}}$ & $\begin{array}{c}\text { Número de trabalhos } \\
\text { selecionados para revisão } \\
\text { sistemática integrativa a } \\
\text { partir da leitura dos } \\
\text { agentes indexadores das } \\
\text { publicações (tema, } \\
\text { descrição, ementa). }\end{array}$ \\
\hline $4^{\mathrm{a}}$ & $\begin{array}{c}\text { Categorias obtidas com a } \\
\text { análise dos documentos } \\
\text { investigados online } \\
\text { gratuitos e de livre acesso }\end{array}$ \\
\hline $5^{\mathrm{a}}$ & $\begin{array}{c}\text { Análise, interpretação e } \\
\text { discussão dos resultados }\end{array}$ & \\
\hline $6^{\mathrm{a}}$ & $\begin{array}{c}\text { Apresentação da revisão } \\
\text { em formato de artigo, o } \\
\text { qual contemple propostas } \\
\text { para estudos futuros }\end{array}$ & Ver em "Resultados e Discussão" \\
\hline
\end{tabular}

Fonte: elaborada pelos autores. 


\section{RESULTADOS}

QUADRO 2

QUANTITATIVO CORRESPONDENTE AO TOTAL DE ARTIGOS CIENTÍFICOS DISPONÍVEIS NAS PLATAFORMA PESQUISADAS POR MEIO DAS STRINGS DE BUSCA LISTADAS NO QUADRO 1.

\begin{tabular}{|c|c|c|c|c|}
\hline String de busca & Bases de dados & $\begin{array}{c}\text { Total de publicações } \\
\text { sem o filtro }\end{array}$ & $\begin{array}{c}\text { Publicações disponíveis } \\
\text { após aplicar os filtros }\end{array}$ & $\begin{array}{c}\text { Publicações aproveitadas na } \\
\text { Revisão Sistemática Integrativa }\end{array}$ \\
\hline $\begin{array}{c}\text { SIG And } \\
\text { Abastecimento } \\
\text { Abastecimento de água } \\
\text { And Indicadores de } \\
\text { desempenho Sistema de } \\
\text { informação geográfica } \\
\text { And Abastecimento } \\
\text { And Água SIG And }\end{array}$ & Periódico CAPES & 334 & 160 & 3 \\
\cline { 2 - 5 } SAA & Periódico CAPES & 203 & 107 & \\
\cline { 2 - 5 } & Scielo & 3 & 1 & \\
\hline
\end{tabular}




\section{QUADRO 3 \\ DESCRIÇÃO DOS ARTIGOS CIENTÍFICOS SELECIONADOS PARA DISCUSSÃO DE ACORDO COM OS CRITÉRIOS DE INCLUSÃO E EXCLUSÃO APRESENTADOS NO QUADRO 1.}

\begin{tabular}{|c|c|c|c|c|c|}
\hline $\mathbf{N}^{\mathbf{0}}$ & Autor(a) & Tema & $\begin{array}{c}\text { Link da } \\
\text { publicação }\end{array}$ & $\begin{array}{c}\text { Data de } \\
\text { publicação }\end{array}$ & Conclusão \\
\hline 1 & $\begin{array}{c}\text { Sayonara Costa } \\
\text { de Araújo; José } \\
\text { Adalberto da } \\
\text { Silva Filho; } \\
\text { Gabriela Muricy } \\
\text { de Souza Silva; } \\
\text { Maria do Carmo } \\
\text { de Souza Cabral } \\
\text { Filha; Virgínia } \\
\text { de Fátima } \\
\text { Bezerra } \\
\text { Nogueira }\end{array}$ & $\begin{array}{c}\text { Distribuiçãa } \\
\text { espacial de } \\
\text { indicadores } \\
\text { operacionais de } \\
\text { serviço de } \\
\text { abastecimento de } \\
\text { água no Nordeste } \\
\text { Brasileiro }\end{array}$ & $\begin{array}{l}\text { https://www.g } \\
\text { vaa.com.br/rev } \\
\text { ista/index.php/ } \\
\text { RVADS/article } \\
\text { /view/4470 }\end{array}$ & $28 / 03 / 2016$ & $\begin{array}{l}\text { Através da distribuição espacial dos indicadores operacionais do } \\
\text { serviço de abastecimento de água na Região Nordeste do Brasil, foi } \\
\text { possível identificar de forma mais clara os problemas referentes ao } \\
\text { acesso, consumo e perdas de água. Apesar do Nordeste apresentar um } \\
\text { desempenho geral considerado satisfatório com relação ao índice de } \\
\text { atendimento de água, percebeu-se a desproporcionalidade da } \\
\text { cobertura do serviço entre os estados avaliados. [...] A avaliação } \\
\text { realizada nesta pesquisa mostrou-se ser bastante relevante, pois as } \\
\text { informações explicitas podem ser utilizadas no processo de } \\
\text { planejamento e gestão dos serviços de abastecimento de água, bem } \\
\text { como servir como base para outros estudos com interesse em avaliar } \\
\text { a qualidade dos serviços de saneamento básico, sobretudo no que se } \\
\text { refere a utilização dos recursos hídricos no Nordeste brasileiro. }\end{array}$ \\
\hline 2 & $\begin{array}{l}\text { Robson Raposo } \\
\text { Macedo, } \\
\text { Ronaldo Lopes } \\
\text { Rodrigues } \\
\text { Mendes, Tony } \\
\text { Costa }\end{array}$ & $\begin{array}{c}\text { Sistema de } \\
\text { informação } \\
\text { geográfica (sig) } \\
\text { aplicado a gestão } \\
\text { de recursos } \\
\text { naturais. Atlas do } \\
\text { aproveitamento de } \\
\text { água da chuva nas } \\
\text { ilhas de Belém - } \\
\text { iniciativas, } \\
\text { demandas e } \\
\text { potencialidades }\end{array}$ & $\begin{array}{l}\text { https://www.e- } \\
\text { publicacoes.ue } \\
\text { rj.br/index.php } \\
\text { /geouerj/article } \\
\text { /view/29876 }\end{array}$ & $31 / 05 / 2018$ & $\begin{array}{l}\text { O artigo apresentado mostra que a utilização de SIG na gestão de } \\
\text { recursos hídricos, vinculado aos } \\
\text { instrumentos governamentais de gestão ambiental, incluindo } \\
\text { processos relacionados à captação e uso da água de chuva, pode ser } \\
\text { uma importante ferramenta de auxílio à gestão por permitir o } \\
\text { aprimoramento dos processos de tomada de decisão a partir da } \\
\text { representação das informações disponibilizadas na base de dados, } \\
\text { apresentada em mapas geográficos temáticos.[...] Revela-se } \\
\text { importante uma gestão integrada, considerando aspectos } \\
\text { socioeconômicos e ambientais que promovam a continuidade de } \\
\text { estudos de acompanhamento de projetos alternativos de captação e } \\
\text { uso da água de chuva, qualidade da água consumida e investimento } \\
\text { em novas pesquisas no que se trata de técnicas de tratamento da água }\end{array}$ \\
\hline
\end{tabular}




\begin{tabular}{|c|c|c|c|c|c|}
\hline & & & & & $\begin{array}{l}\text { de chuva para o consumo humano quando na análise laboratorial das } \\
\text { amostras coletadas observou-se que ainda existe uma carência no } \\
\text { processo de tratamento da água consumida nas ilhas. Essa pesquisa } \\
\text { também permitiu a elaboração de um banco de dados com } \\
\text { informações georreferenciadas sobre os tipos de sistemas de captação } \\
\text { instalados, qualidade das águas consumidas nas ilhas e informações } \\
\text { socioambientais das áreas pesquisadas }\end{array}$ \\
\hline 3 & $\begin{array}{c}\text { Carlos Wilmer } \\
\text { Costa Reinaldo } \\
\text { Lorandi José } \\
\text { Augusto Di } \\
\text { Lollo Vagner de } \\
\text { Souza Serikawa }\end{array}$ & $\begin{array}{l}\text { Combinação de } \\
\text { atributos naturais e } \\
\text { antrópicos na } \\
\text { definição do } \\
\text { potencial de } \\
\text { contaminação de } \\
\text { aquíferos, sudeste } \\
\text { do Brasil }\end{array}$ & $\begin{array}{l}\text { http://www.see } \\
\text { r.ufu.br/index. } \\
\text { php/sociedade } \\
\text { natureza/article } \\
\text { /view/56221 }\end{array}$ & $26 / 08 / 2020$ & $\begin{array}{c}\text { A bacia hidrográfica do Rio Claro apresentou elevado índice de } \\
\text { potencial de contaminação de aquíferos para o período analisado. Em } \\
1994 \text { as classes de potencial de contaminação alto e muito alto } \\
\text { abrangeram } 46,1 \% \text { da área da bacia enquanto que em 2014, esse } \\
\text { percentual aumentou para } 48,6 \% \text {. [...] Quando considerados os } \\
\text { impactos da variação do uso e cobertura da terra sobre o potencial de } \\
\text { contaminação, constatou-se que a } \\
\text { intercalação entre o cultivo da cana-de-açúcar e solo exposto } \\
\text { (preparado para o cultivo) foi } \\
\text { fundamental para que se mantivesse o elevado potencial de } \\
\text { contaminação dos aquíferos. Desta forma, é patente a necessidade de } \\
\text { adoção de } \\
\text { práticas conservacionistas no cultivo de cana, especialmente no } \\
\text { período entressafras, para minimizar os impactos ambientais } \\
\text { negativos desta cultura. }\end{array}$ \\
\hline 4 & $\begin{array}{c}\text { Rafaela } \\
\text { Schramm Viana } \\
\text { Bruno Parente } \\
\text { Leitão de Castro } \\
\text { Erika da Justa } \\
\text { Teixeira Rocha1 }\end{array}$ & $\begin{array}{l}\text { Utilização do SIG } \\
\text { para a avaliação de } \\
\text { indicadores de } \\
\text { saneamento na } \\
\text { Região } \\
\text { Metropolitana de } \\
\quad \text { Fortaleza }\end{array}$ & $\begin{array}{c}\text { https://orcid.or } \\
\text { g/0000-0002- } \\
4743-950 \mathrm{X}\end{array}$ & $29 / 08 / 2019$ & $\begin{array}{l}\text { Com o uso de SIG foi possível espacializar os dados de saneamento } \\
\text { dos municípios da RMF e obter sua visualização por meio de mapas } \\
\text { temáticos, de maneira simples e direta. Essa ferramenta apresentou-se } \\
\text { como um importante recurso } \\
\text { para utilização e interpretação dos indicadores, de modo a avaliar o } \\
\text { desempenho e auxiliar na gestão dos serviços de saneamento. [...] No } \\
\text { que concerne ao índice de universalização do saneamento básico, } \\
\text { observou-se que todos } \\
\text { os municípios da RMF apresentaram valores insatisfatórios, atingindo } \\
\text { menos de } 80 \% \text {, com o alarmante resultado de } 16,26 \% \text { para o }\end{array}$ \\
\hline
\end{tabular}




\begin{tabular}{|c|c|c|c|c|c|}
\hline & & & & & $\begin{array}{l}\text { município de Trairi. Esse valor denota um total descaso com o } \\
\text { saneamento básico, o qual reflete diretamente na preservação da } \\
\text { saúde pública, na melhoria da economia e no meio ambiente. }\end{array}$ \\
\hline 5 & $\begin{array}{c}\text { Bernardo Costa } \\
\text { Mundim Isaac } \\
\text { Volschan Junior }\end{array}$ & $\begin{array}{l}\text { Avaliação dos } \\
\text { indicadores de } \\
\text { desempenho } \\
\text { operacionais e de } \\
\text { qualidade do } \\
\text { Sistema Nacional } \\
\text { de Informações } \\
\text { sobre Saneamento } \\
\text { para sistemas de } \\
\text { abastecimento de } \\
\text { água e esgotamento } \\
\text { sanitário }\end{array}$ & $\begin{array}{c}\text { https://orcid.or } \\
\text { g/0000-0003- } \\
0879-3650\end{array}$ & $30 / 07 / 2019$ & $\begin{array}{l}\text { Indicadores de desempenho são utilizados por diversos sistemas } \\
\text { nacionais e internacionais de avaliação, o que demonstra a } \\
\text { importância dessa ferramenta na avaliação de sistemas de } \\
\text { abastecimento de água e esgotamento sanitário. No entanto, sua } \\
\text { utilização deve ser realizada com criticidade, sempre observando, } \\
\text { além dos resultados apresentados pelos indicadores, as diversas } \\
\text { variáveis que influenciam esses resultados e que muitas das vezes não } \\
\text { estão incorporadas aos indicadores. [...] Diante do exposto, este } \\
\text { estudo contribui para o questionamento sobre a relevância, } \\
\text { aplicabilidade e o efetivo objetivo de alguns indicadores que constam } \\
\text { na base SNIS, que é o maior e mais importante banco de dados do } \\
\text { setor de saneamento brasileiro. }\end{array}$ \\
\hline 6 & $\begin{array}{l}\text { Aline Christian } \\
\text { Pimentel } \\
\text { Almeida Santos } \\
\text { José Almir } \\
\text { Rodrigues } \\
\text { Pereira }\end{array}$ & $\begin{array}{c}\text { SIG no } \\
\text { gerenciamento de } \\
\text { SAAS }\end{array}$ & $\begin{array}{l}\text { http://revistada } \\
\text { e.com.br/artigo } \\
\text { s/artigo_edicao } \\
\text { 202_n_1641. } \\
\text { pdf }\end{array}$ & $01 / 12 / 2015$ & $\begin{array}{l}\text { A proposta de utilização de SIG para espacialização, armazenamento } \\
\text { e controle dos dados de SAAs possibilitou o conhecimento e a análise } \\
\text { espacial do desempenho do SAA estudado. A organização e a } \\
\text { espacialização de dados facilitaram a visualização dos problemas, } \\
\text { auxiliando na tomada de decisão na concessionária de saneamento, } \\
\text { além de ajudar a evitar e reduzir gastos. [...] Do mesmo modo, a } \\
\text { determinação das despesas de exploração e a avaliação do } \\
\text { desempenho comercial, em relação ao faturamento e arrecadação dos } \\
\text { SAAs, podem auxiliar os gestores na elaboração do planejamento e } \\
\text { na tomada de decisão, além de permitir a sustentabilidade do SAA e } \\
\text { promover o cumprimento da Lei no } 11.445 / 2007 \text {. Assim, a } \\
\text { espacialização de informações de desempenho é recomendada para o } \\
\text { planejamento e tomada de decisão, sendo uma importante ferramenta } \\
\text { para os gestores, técnicos e colaboradores de empresas de } \\
\text { saneamento. }\end{array}$ \\
\hline 7 & $\begin{array}{l}\text { Willer Fagundes } \\
\text { de Oliveira }\end{array}$ & $\begin{array}{l}\text { Dinâmica do uso e } \\
\text { ocupação do solo }\end{array}$ & $\begin{array}{l}\text { http://www.see } \\
\text { r.ufu.br/index. }\end{array}$ & $02 / 02 / 2016$ & $\begin{array}{l}\text { A descrição cronológica da dinâmica do uso e ocupação do solo na } \\
\text { área de drenagem do reservatório do Sistema Juramento foi possível }\end{array}$ \\
\hline
\end{tabular}




\begin{tabular}{|c|c|c|c|c|c|}
\hline & $\begin{array}{c}\text { Rafael } \\
\text { Alexandre Sá } \\
\text { Marcos Esdras } \\
\text { Leite }\end{array}$ & $\begin{array}{c}\text { na área de } \\
\text { drenagem do } \\
\text { reservatório de } \\
\text { abastecimento do } \\
\text { sistema } \\
\text { juramento/mg }\end{array}$ & $\begin{array}{c}\text { php/caminhosd } \\
\text { egeografia/ }\end{array}$ & & $\begin{array}{l}\text { através dos mapas temáticos confeccionados pela técnica de SIG, } \\
\text { com dados obtidos pelos produtos do sensoriamento remoto. As } \\
\text { imagens de satélites permitem o mapeamento espaço-temporal, a } \\
\text { partir de séries históricas de imagens de média resolução espacial. } \\
\text { Com as informações geradas por esses recursos tecnológicos pode-se } \\
\text { entender a dinâmica de uso do solo e de transformação da paisagem } \\
\text { natural. [...] Dessa forma, os resultados obtidos neste trabalho são } \\
\text { importantes, pois revelam um quadro de aumento da retirada da } \\
\text { vegetação natural e crescimento da ocupação da terra para atividades } \\
\text { agropecuárias. Esse cenário se agrava, uma vez que se trata da área de } \\
\text { drenagem do principal reservatório de água da maior cidade do norte } \\
\text { de Minas Gerais, ou seja, Montes Claros. Portanto, os resultados } \\
\text { desse trabalho, no que concerne ao uso e ocupação do solo, poderão } \\
\text { contribuir com as pesquisas hidroambientais e gestão de recursos } \\
\text { hídricos na área de estudo, subsidiar projetos e ações de conservação } \\
\text { da área de drenagem do Sistema Juramento, além a orientação de } \\
\text { utilização racional desse espaço. }\end{array}$ \\
\hline 8 & $\begin{array}{c}\text { Francisco Eudes } \\
\text { do Amaral José } \\
\text { Almir Cirilo } \\
\text { Alfredo Ribeiro } \\
\text { Neto }\end{array}$ & $\begin{array}{l}\text { Uso de técnicas de } \\
\text { geoprocessamento } \\
\text { na otimização do } \\
\text { traçado de sistemas } \\
\text { adutores de } \\
\text { abastecimento de } \\
\text { água com a } \\
\text { utilização de uma } \\
\text { base de dados de } \\
\text { alta definição }\end{array}$ & $\begin{array}{l}\text { http://www.sci } \\
\text { elo.br/j/esa/a/8 } \\
\text { 5NqLZXL4TQ } \\
\text { K4jk5kVJKVb } \\
\text { N/abstract/?lan }\end{array}$ & $11 / 03 / 2019$ & $\begin{array}{l}\text { No que concerne à seleção dos locais com potencial para locação do } \\
\text { traçado da adutora, a metodologia apresenta-se como alternativa à } \\
\text { padronização e à ponderação dos planos de informações (variáveis } \\
\text { espaciais) utilizados. Esse procedimento proporciona o tratamento } \\
\text { estatístico da opinião de vários especialistas com relação aos critérios } \\
\text { estabelecidos, auxilia na minimização de avaliações tendenciosas e } \\
\text { permite a análise de critérios que se utilizam de múltiplas grandezas. } \\
\text { Não obstante, a metodologia pode ser utilizada no desenvolvimento } \\
\text { de projetos de adutoras em outras regiões, desde que dados e } \\
\text { informações estejam disponíveis. [...] Por fim, é importante salientar } \\
\text { a necessidade do desenvolvimento de aplicações que incluam outros } \\
\text { critérios de tomada de decisão para a locação do traçado de adutoras, } \\
\text { como tipo de solo, visto que o custo com a escavação tem elevado } \\
\text { peso na composição do custo total da obra. Outra sugestão seria o } \\
\text { aperfeiçoamento do critério que melhor representa o consumo de }\end{array}$ \\
\hline
\end{tabular}




\begin{tabular}{|c|c|c|c|c|c|}
\hline & & & & & $\begin{array}{l}\text { energia com bombeamento. Embora tenha havido bastante coerência } \\
\text { entre os traçados obtidos com as condições do relevo e mesmo com } \\
\text { as soluções definidas nos projetos de engenharia, é importante } \\
\text { desenvolver análise de sensibilidade quanto aos valores dos pesos } \\
\text { utilizados, visto que sempre existe o componente de subjetividade. }\end{array}$ \\
\hline 9 & $\begin{array}{l}\text { Maria José de } \\
\text { Sousa Cordão } \\
\text { Iana Alexandra } \\
\text { Alves Rufino } \\
\text { Ester Luiz de } \\
\quad \text { Araújo }\end{array}$ & $\begin{array}{c}\text { Geotecnologias } \\
\text { aplicadas ao } \\
\text { planejamento de } \\
\text { sistemas de } \\
\text { abastecimento de } \\
\text { água urbanos: uma } \\
\text { proposta } \\
\text { metodológica }\end{array}$ & $\begin{array}{l}\text { http://www.sci } \\
\text { elo.br/j/esa/a/q } \\
\text { fDJB9hd9NM } \\
\text { 7JPjgV866M } \\
\text { Wv/abstract/?1 } \\
\text { ang=pt }\end{array}$ & $22 / 07 / 2016$ & $\begin{array}{l}\text { O mapeamento de lotes com riscos de desabastecimento pode } \\
\text { funcionar como indicador para ações de gestão e planejamento, visto } \\
\text { que sugere que uma parcela dos usuários de água encontra-se em } \\
\text { áreas com regime deficiente de abastecimento, seja por questões } \\
\text { operacionais, demográficas ou geográficas. Os resultados das áreas } \\
\text { ótimas para a disposição de novas unidades de reservação auxiliam } \\
\text { na tomada de decisão, trazendo diretrizes de planejamento em virtude } \\
\text { da expansão do sistema estudado (o estudo não alcançou a etapa de } \\
\text { definir dados em microescala acerca da localização exata dos novos } \\
\text { reservatórios e quanto seriam seus volumes). A obtenção dessas } \\
\text { diretrizes para o planejamento dos SUDA na área de estudo escolhida } \\
\text { visa minimizar custos, aumentando a eficiência e alcance social do } \\
\text { serviço prestado. }\end{array}$ \\
\hline 10 & $\begin{array}{c}\text { Germana Leite } \\
\text { Gonzalez } \\
\text { Toscano Tarciso } \\
\text { Cabral da Silva }\end{array}$ & $\begin{array}{c}\text { Uso do solo em } \\
\text { zonas de proteção } \\
\text { de poços para } \\
\text { abastecimento } \\
\text { público na cidade } \\
\text { de João Pessoa } \\
\text { (PB) }\end{array}$ & $\begin{array}{l}\text { https://www.re } \\
\text { adcube.com/art } \\
\text { icles/10.1590 } \\
\% 2 \text { Fs } 1413- \\
415220120004 \\
00001\end{array}$ & $20 / 12 / 20$ & $\begin{array}{l}\text { A questão da água para abastecimento público a partir de captações } \\
\text { de águas subterrâneas tem merecido a atenção dos gestores do setor } \\
\text { de saneamento básico apenas concernente aos aspectos quantitativos. } \\
\text { No Brasil, e em particular em algumas cidades litorâneas do } \\
\text { Nordeste, têm ocorrido diversos problemas de qualidade de água } \\
\text { decorrentes do uso inadequado do solo urbano nas áreas influentes na } \\
\text { recarga dos poços de captação de águas subterrâneas.[...] Espera-se, } \\
\text { em um futuro próximo, que os gestores públicos dos recursos hídricos } \\
\text { realizem ações preventivas visando evitar inadequações futuras com a } \\
\text { qualidade das águas subterrâneas, e ações corretivas para controlar a } \\
\text { ameaça de contaminação ou poluição representada por atividades } \\
\text { passadas e presentes, estabelecendo prioridades realistas e } \\
\text { implementação eficiente. }\end{array}$ \\
\hline
\end{tabular}

Fonte: elaborada pelos autores. 
Após o preenchimento do Quadro 3, utilizam-se as conclusões dos artigos para a realização da análise por meio da frequência de palavras, criando a nuvem de palavras apresentada na Figura 1. A nuvem foi confeccionada na plataforma online
WordArt., ferramenta a qual agrupa e organiza graficamente as palavras-chave evidenciando as mais frequentes e que, portanto, deu subsídio para confecção das categorias de discussões.

\section{FIGURA 1}

NUVEM DE PALAVRAS CONFECCIONADA COM BASE NAS CONCLUSÕES DOS ARTIGOS DESCRITOS NO QUADRO 3.

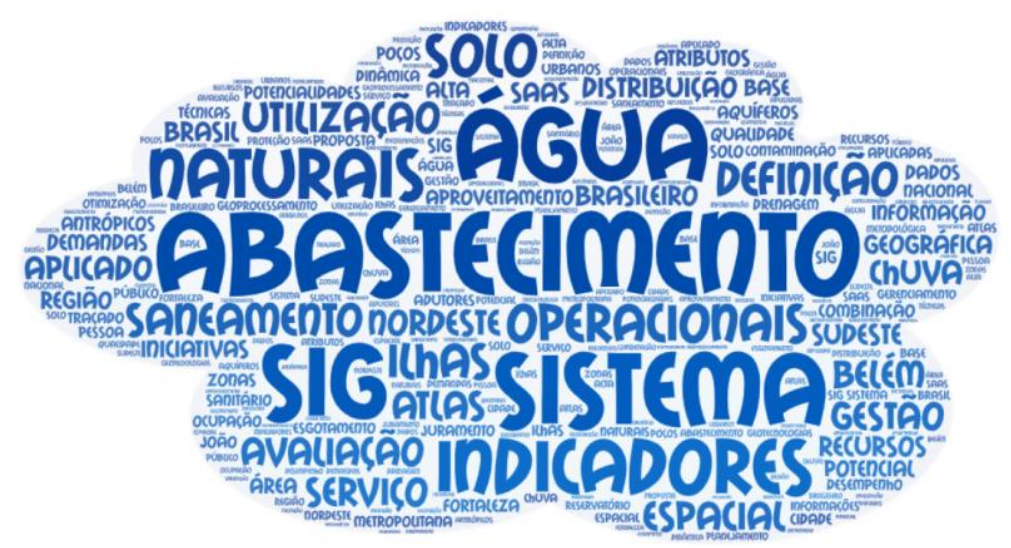

Fonte: elaborada pelos autores.

Ainda através da (Figura 1), foi possível ver que as palavras em evidência na nuvem pertencem às categorias desenvolvidas a partir da análise de conteúdo de Bardin. Todas as categorias derivam da sua frequência (Tabela 1), que diz respeito ao seu quadro referencial. Em consonância ao objetivo deste trabalho, optou-se por descrever as palavras que apresentaram frequência total nas conclusões dos artigos e, a partir de seus sentidos nos campos textuais. Diante disto, foi feita uma análise de relevância das palavras para melhor discussão das temáticas relacionadas aos SAAs, assim como a incorporação do SIG nesses sistemas.

Tabela 1

FREQUÊNCIA DAS PALAVRAS PRESENTES NAS CONCLUSÕES DOS

TRABALHOS LISTADOS NO QUADRO 3.

\begin{tabular}{c|c|c}
\hline PALAVRAS & FREQUÊNCIA & CATEGORIAS \\
\hline Abastecimento & 6 & 12 \\
\hline Sistema & 3 & 5 \\
\hline Água & 5 & 5 \\
\hline Indicadores & 3 & 8 \\
\hline SIG & 3 & 1 \\
\hline Operacionais & 2 & 0 \\
\hline Naturais & 2 & 5 \\
\hline
\end{tabular}

Oliveira et al. 


\begin{tabular}{|c|c|c|}
\hline Saneamento & 2 & 6 \\
\hline Solo & 2 & 0 \\
\hline Distribuição & 1 & 0 \\
\hline Serviço & 1 & 0 \\
\hline Nordeste & 1 & 0 \\
\hline Brasileiro & 1 & 0 \\
\hline Informação & 1 & 10 \\
\hline Geográfica & 1 & 7 \\
\hline Gestão & 1 & 8 \\
\hline Recursos & 1 & 5 \\
\hline Aproveitamento & 1 & 3 \\
\hline Chuva & 1 & 4 \\
\hline Demandas & 1 & 0 \\
\hline Potencialidades & 1 & 2 \\
\hline Combinação & 1 & 1 \\
\hline Potencial & 1 & 3 \\
\hline Contaminação & 1 & 2 \\
\hline Aquíferos & 1 & 0 \\
\hline Desempenho & 1 & 0 \\
\hline Qualidade & 1 & 3 \\
\hline Nacional & 1 & 0 \\
\hline Informações & 1 & 3 \\
\hline Esgotamento & 1 & 4 \\
\hline Sanitário & 1 & 1 \\
\hline Gerenciamento & 1 & 3 \\
\hline SAAS & 1 & 5 \\
\hline Dinâmica & 1 & 0 \\
\hline Ocupação & 1 & 1 \\
\hline Área & 1 & 2 \\
\hline Drenagem & 1 & 7 \\
\hline Reservatório & 1 & 4 \\
\hline Técnicas & 1 & 0 \\
\hline Geoprocessamento & 1 & 2 \\
\hline Otimização & 1 & 0 \\
\hline Traçado & 1 & 0 \\
\hline Adutores & 1 & 6 \\
\hline Base & 1 & 3 \\
\hline Dados & 1 & 0 \\
\hline Geotecnologias & 1 & 0 \\
\hline Planejamento & 1 & 2 \\
\hline Público & 1 & 2 \\
\hline Cidade & 1 & 0 \\
\hline
\end{tabular}

Fonte: elaborada pelos autores. 


\section{DISCUSSÕES}

\section{Sistemas de Informações Geográficas (SIG)}

O geoprocessamento pode ser compreendido como um conjunto de tecnologias que tem como principal objetivo colher e apresentar dados espaciais para um fim específico. A aplicação de geoprocessamento é organizada por um sistema específico, conhecido como Sistema de Informações Geográficas (SIG).

O processamento de dados de um sistema de geoprocessamento tem como finalidade coletar dados referenciados geograficamente, desde a sua coleta até a geração e a exibição das informações, que ocorre por intermédio de mapas convencionais, arquivos digitais, relatórios e gráficos, entre outras informações.(SANTOS; PEREIRA, 2016).

Para a evolução da história o Sistemas de Informações Geográficas está inteiramente relacionada com as diversas fases do desenvolvimento da humanidade em busca aprimorar a representação do seu mundo real.

Para Röhm (2017, p.1), uma das primeiras funcionalidades dos SIGs ocorreram no século XX no início dos anos sessenta, onde buscavam soluções para os problemas encontrados no gerenciamento de dados espaciais georreferenciados, inerentes ao uso da terra, das análises ambientais juntamente com dos recursos naturais.

Para Harris (2016), a definiçãa para o sistema de informações geográficas pode ser através das realizações de coletas e armazenamentos de dados, assim como recuperar informações espaciais, identificando locais onde pertencem a um determinado dado ambiental, segundo algum critério pré-definido. Ainda assim, explorar os conjuntos de relações de dados com um determinado dado ambiente é bem eficaz, pois analisa as informações afim de auxiliar a tomada de decisões sobre o ambiente.

Pode-se dizer, de modo geral que o Geoprocessamento é uma ferramenta de trabalho que é importante para seu processo informativo, onde aparece, dentre as questões e problemas que precisam ser resolvidos por um sistema informatizado, haverá uma oportunidade para considerar a adoção de um SIG (CÂMARA, 2017).

\section{Sistema de abastecimento de água}

O sistema de abastecimento e distribuição de água é caracterizado como um conjunto de infraestruturas constituídos por obras de construção civil, em que são utilizados equipamentos elétricos e eletromecânicos, instrumentação, acessórios e equipamentos de automação e controle. Cada órgão num sistema de abastecimento e distribuição de água tem um objetivo/função (SOUSA, 2020).

Dessa forma, é valido salientar que o Sistema de Abastecimento de Água (SAA) é um sistema considerada em "alta" que é constituído por um conjunto de elementos a montante da rede de distribuição de água, fazendo com que exista uma ligação do meio hídrico ao sistema em "baixa". O sistema de abastecimento de água é um sistema em "baixa" se é constituído por um conjunto de componentes que ligam o sistema em "alta" ao utilizador final. $\mathrm{O}$ sistema de abastecimento de água presta um serviço em "alta" e em "baixa" 
sempre que vincula o meio hídrico a um utilizador final (IP, 2018).

O tratamento prévio ao consumo humano é de extrema importância, pois é a forma de assegurar que a água depois de tratada não representará qualquer perigo para a saúde humana. Qualquer água que seja superficial ou subterrânea carece de tratamento adequado para serem distribuídos corretamente para a população. Podendo apresentar certos perigos para os consumidores, com uma água de baixa qualidade, resultando assim numa eventual contaminação microbiológica, química, física ou até mesmo radioativa (WHO, 2019).

Sendo assim, para a maior parte dos sistemas de tratamento são preparados para remover as contaminações microbiológicas e os constituintes que prejudica a aceitabilidade da mesma, onde muitas vezes pode estar associada à presença de sólidos suspensos na água. A desinfeção também está presente em quase todos os tipos de sistemas de tratamento, independentemente do seu tamanho ou complexidade.

Para isso as águas superficiais são captadas através de rios e lagos, onde os rios apresentam variações bruscas na qualidade da água. Sobretudo quando ocorre a mudança das estações climatéricas, é afetáveis por descargas de contaminantes, ao passo que os lagos aumentam. É valido destacar também que os principais inconvenientes a estratificação no verão estão voltados a um processo de eutrofização que em muitos casos pode ser muito acentuado (REGO, 2020).
Geoprocessamento e o meio ambiente

O Geoprocessamento pode ser considerado como uma disciplina do conhecimento que usa técnicas computacionais e matemáticas para a análise de informação geográfica, onde pode ser influenciando de maneira progressiva áreas da cartografia, juntamente com a análise de recursos naturais, comunicações, transportes, urbano e regional e energia e planejamento.

O Sistemas de Informação Geográfica (SIG) utiliza de ferramentas computacionais para geoprocessamento, permitindo realização de uma análise mais aprofundada ao integrar dados de diversas fontes e ao criar bancos de dados georeferenciados.

Com essa ferramenta ainda é possível automatizar a aceleração de muitos documentos cartográficos, visibilizando o modelo de representação do ambiente com característica do ambiente. O denominado "Mundo Real". Com isso, ele ainda reformula uma forma mais familiar que simplificada e torna cada vez mais acessível de ser observada, podendo ainda ser facilmente representada ou controlada, de maneira que possa extrair informações replicadas ao "Mundo Real" (Ambiente) para melhor entendimento e gerenciamento. (MENDES \& CIRILO, 2018).

\section{Aplicação do SIG em Sistema de Abastecimento de águas}

Para Junqueira, Lautenschlager e Paredes (2019), a aplicação de SIG é apoio à gestão de companhias de saneamento, pois é através dele que é possível fazer obter com facilidade informações para os clientes, 
colaborando com projetos $\mathrm{e}$ planejamento, aperfeiçoando dede já a operação e manutenção do sistema hidráulico, que pode indica pontos críticos, além de gerencia a infraestrutura utilizada e a estrutura administrativa. Então em um SAA, existem diferentes tipos de dado e informações específicas necessários para apresentação de uma boa gestão.

Assim, é abrangível que todos os setores da empresa tenham suas informações armazenadas e interligadas no SIG, como o setor comercial (com o sistema de informação de clientes), de projetos e planejamento, operacional (com o registro de operações, manutenções e estado da rede de distribuição e equipamentos), de infraestrutura, de fugas e administrativo. (SANTOS; PEREIRA, 2016).

Para Santos (2018) o controle de perdas em rede de distribuição de água utilizando SIG, é fundamental, para que haja uma organização das informações, tanto os referentes à cartografia da área que se pretende monitorar, como as dos dados necessários para a realização de tal monitoramento, isto é, informações cartográficas e dados e informações técnicos.

A utilização de SIG em SAA foi realizado para a recuperação de vazamentos do terceiro do setor de abastecimento de água, sendo assim, é valido ressaltar a importância da manutenção preventiva, uma vez que dados preexistentes sobre execução de serviços de manutenção corretiva em redes de distribuição de água estão disponíveis para subsidiar processos de gestão de manutenção preventiva nessas redes.

\section{CONCLUSÃO}

Com o desenvolvimento do presente estudo pôde-se concluir que o Sistema de Informações geográficas são meios de utilização por diversos sistemas nacionais e internacionais de avaliação, demostrando desde já a importância dessa ferramenta na avaliação de sistemas de abastecimento de água e esgotamento sanitário não só no Brasil mais também no mundo.

Com o auxílio das ferramentas de SIG, pode ser construídos indicadores para uma melhor avaliação do desempenho das SAAs, com a finalidade avaliar o uso da ferramenta e sua organização quanto a espacialização de dados que facilitam a visualização dos problemas, auxiliando na tomada de decisão na concessionária de saneamento, além de ajudar a evitar e diminuir os eventuais gastos.

Sendo assim, para a determinação dos gastos de exploração e a avaliação do desempenho comercial, em relação ao faturamento e arrecadação dos SAAs, propicia para os gestores uma melhor elaboração do planejamento e na tomada de decisão, além de promover a sustentabilidade do SAA e fazer-se o cumprimento da Lei n ${ }^{\circ} 11.445 / 2007$.

Diante disso, o artigo mostra-se relevante ao se considerar que a Lei $\mathrm{n}^{\circ}$ $11.445 / 2007$ estabelece o instrumento de avaliação de desempenho da prestação de serviços de abastecimento de água e esgotamento sanitário em nosso país, sendo os indicadores uma ferramenta extremamente necessária para tal. com mais facilidade e a obtenção de informações mais precisas e organizadas, além da análise do 
desempenho por sistema, por setor ou por unidade do SAA.

Este estudo contribui para o questionamento sobre a relevância, aplicabilidade e o efetivo objetivo de alguns indicadores quanto a utilização do SIG para o gerenciamento de SAAs

\section{REFERÊNCIAS}

INSTITUTO TRATA BRASIL.

\section{Benefícios econômicos e sociais da expansão do saneamento no Brasil.}

2018. Disponível em:

$<$ http://tratabrasil.org.br/estudos/estudos -itb/itb/beneficios-economicos-esociais-da-expansao-do saneamentobrasileiro>. Acesso em: 11 mai. 2021.

LACERDA, I.S. (2019) Regras de operação para sistemas de abastecimento de água com baixo nível de automação e sujeitos a incertezas. Dissertação (Mestrado em Engenharia Civil e Ambiental) - Universidade Federal de Campina Grande, Campina Grande.

MUNDOGEO. (2018). Sistemas de Informações Geográficas na Operação Sistemas de Distribuição de Água comunidade urbana.

OLIVEIRA, M. (2016). O uso de Sistemas de Informações Geográficas na Operação de Sistemas de Distribuição de Água. Disponível em:< https://mundogeo.com/2000/01/01/ouso-de-sistemas-de-informacoesgeograficas-na-operacao-de-sistemasde-distribuicao-de-agua/>. Acesso em: 09 mai. 2021.

SANTOS, A. C. P. A.; PEREIRA, J. A. R. Sig No Gerenciamento De Sistemas De Abastecimento De Água. Revista possibilitando a visualização dos dados e dos resultados com mais facilidade e a obtenção de informações mais precisas e organizadas para tomada de decisão, que é o maior e mais importante banco de dados do setor de saneamento brasileiro.

DAE, v. 64, n. 202, p. 76-86, 2016.

SOUSA, E. (2020). Sistemas de Abastecimento de Água. Departamento de Engenharia Civil e Arquitectura. Lisboa: Instituto Superior Técnico.

(IP) Informação Portugal, (2018). Abastecimento de Água e Saneamento de Águas Residuais. Lisboa: Águas de Portugal, INAG e IRAR.

REGO, Paulo (2004). Guia Ambidata para Sistemas de Tratamento de Água para Consumo Humano.

Porto:Ambidata, Lda.

MENDES, C. A. B. \& CIRILO, J. A. Geoprocessamento em recursos hídricos, princípios, integração e aplicação. $1^{a}$ Edição. Porto Alegre: ABRH, 2018. 536p.

JUNQUEIRA, R. F.; LAUTENSCHLAGER, S. R.; PAREDES, E. A. "Aplicação de SIG na gestão da manutenção de redes de Distribuição de água”. In: Congresso Brasileiro de Engenharia Sanitária e Ambiental, 25., 2009, Recife. Anais ... Recife: ABES, 2009. 1 CDROM.

SANTOS, A. C. P. A.; PEREIRA, J. A. R. Sig No Gerenciamento De Sistemas De Abastecimento De Água. Revista DAE, v. 64, n. 202, p. 76-86, 2016. 
SANTOS, Aline C. P. A. Sistemas de

Informações Geográficas no

Monitoramento e Recuperação de

Vazamentos em Redes de Distribuição

de Água. 2018. 92 f. Trabalho de

Conclusão de Curso (Graduação em

Engenharia Sanitária) - Instituto de

Tecnologia, Universidade Federal do

Pará, Belém, 2018. 